\title{
Effect of penicillin and spectinomycin given for urethritis and cervicitis with Neisseria gonorrhoeae: high prevalence of penicillin-resistant isolates
}

\author{
Y H KOURI, L GONZÁLEZ, M PÉREZ, R MENAR, C R GADEA, E KRAISELBURD, \\ L J TORRES-BAUZA \\ From the Harvard Institute for International Development, Latin American Center for Sexually Transmitted \\ Diseases, Health Department of the Commonwealth of Puerto Rico, and Department of Microbiology and \\ Medical Zoology School of Medicine, University of Puerto Rico, Puerto Rico
}

SUMMARY Efficacy of single-dose spectinomycin (TRO: $2 \mathrm{~g}$ intramuscularly) was compared with that of aqueous procaine penicillin G (APPG: $4.8 \times 10^{6}$ units) plus $1 \mathrm{~g}$ of probenecid for treatment of gonococcal urethritis and cervicitis. Cure rates of the 210 patients who received TRO and 190 patients who received APPG were $97.6 \%$ and $91 \cdot 1 \%$, respectively. MICs of antibiotics were determined using the agar dilution method. Those isolates with MICs of APPG of $<1.0 \mu \mathrm{g} / \mathrm{ml}$ had low failure rates $(2.9 \%)$, while strains with increased resistance to APPG (MICs $\geqslant 1.0 \mu \mathrm{g} / \mathrm{ml}$ ) had higher failure rates (24\%). Treatment failures seen with TRO were not correlated to isolates with the higher MICs. Clinical results suggest TRO could be given for treatment of genital gonorrhoea in Puerto Rico due to the high prevalence of both chromosomally-mediated penicillin-resistant Neisseria gonorrhoeae $(20 \%)$ and penicillinase-producing Neisseria gonorrhoeae $(7 \cdot 5 \%)$ strains and the high rate of failure seen with the use of APPG.

The failure of penicillin and spectinomycin regimens in the clinical setting are known to vary according to geographic location. ${ }^{1-3}$ The reports of significant spatial and prevalence variation in the distribution of penicillinase-producing Neisseria gonorrhoeae (PPNG), ${ }^{48}$ chromosomally mediated penicillin-resistant Neisseria gonorrhoeae (CMRNG) strains, ${ }^{-11}$ and spectinomycin-resistant isolates ${ }^{12-15}$ are causes for concern among health-care practitioners world-wide. Because of these observations and because of increased travel from the United States, Latin America, and Europe to Puerto Rico, the Latin American Center for Sexually Transmitted Diseases (LACSTD), located in Puerto Rico, decided to compare the efficacy of the penicillin regimen with that of spectinomycin. This study was part of a larger InterAmerican project to monitor gonococcal resistance, a research venture generated by the Pan American Health Organization (PAHO) with the participation of the U.S. Centers for Disease Control in Atlanta, Georgia.

Address for reprints: Dr Luis J Torres-Bauza, MT, PhD, Universidad de Puerto Rico, Recinto de Ciencias Médicas, G.P.O. Box 5067, San Juan, Puerto Rico 09936.

Accepted for publication 27 July 1989

\section{Methodology}

\section{Patients}

In this study, 533 patients with confirmed genital gonorrhoea by culture were enrolled from among persons visiting LACSTD during the period from 1982 to 1984. Patients were invited to participate if they had signs or symptoms of genital infection and gramnegative intracellular diplococci on smear of the discharge or were contact cases from a culture positive patient. Subjects were not invited to participate if pregnant or if they had a history of allergy to penicillin or spectinomycin, evidence of coexistent syphilis, or had received antibiotics within the previous two weeks. All female and male subjects were between 18 and 54 years of age and gave written and informed consent. Clinical evaluation included a work-up for STD, including a clinical history, VDRL test, gramstain, $\mathrm{KOH}$ and wet mount smears, and pretreatment cultures in modified Thayer-Martin.

Patients were assigned by a randomised table to receive either 4.8 million units of intramuscular aqueous procaine penicillin G (APPG) plus $1 \mathrm{~g}$ of oral probenecid or $2 \mathrm{~g}$ of intramuscular spectinomycin (Trobicin). Treatment was initiated immediately after oral, genital and anal specimens were obtained for 
Table 1 Efficacies of penicillin and spectinomycin in the treatment of gonococcal urethritis or cervicitis

\begin{tabular}{|c|c|c|c|c|}
\hline \multirow[b]{2}{*}{ Drug regimen } & \multirow{2}{*}{$\begin{array}{l}\text { Number of } \\
\text { patients enrolled }\end{array}$} & \multicolumn{2}{|c|}{ Test of cure } & \multirow{2}{*}{$\begin{array}{l}\text { Percent of } \\
\text { treatment } \\
\text { failures }\end{array}$} \\
\hline & & Positive & Negative & \\
\hline $\begin{array}{l}\text { Aqueous procaine penicillin plus probenecid } \\
\text { Spectinomycin } \\
\text { Total number of isolates }\end{array}$ & $\begin{array}{l}190 \\
210 \\
400\end{array}$ & $\begin{array}{r}17 \\
5 \\
22\end{array}$ & $\begin{array}{l}173 \\
205 \\
378\end{array}$ & $\begin{array}{l}8 \cdot 9 \\
2 \cdot 4 \\
5 \cdot 5\end{array}$ \\
\hline
\end{tabular}

bacterial isolation and identification. Patients with an oral or rectal gonococcal infection, or a negative genital infection were excluded.

\section{Bacterial isolates}

We obtained 533 pretreatment isolates of Neisseria gonorrhoeae and confirmed their identity by colonial morphology, gram-stain, positive oxidase reaction, and by the coagglutination (Phadebact, Pharmacia Diagnostic, Piscataway, NJ) reaction tests. Identification of clinical isolates was usually completed 48 to 72 hours after specimens were taken. All isolates were tested for beta-lactamase production using the iodometric paper strip test and then frozen in defibrinated rabbit blood at $-80^{\circ} \mathrm{C}$ for further studies. ${ }^{1617}$

\section{Susceptibility testing}

The minimal inhibitory concentration (MICs) for the Neisseria gonorrhoeae isolates were determined using the agar dilution method in which serial two-fold dilutions of the antibiotics were incorporated into Protease Number 3 Agar Base (GIBCO Laboratories, Madison, WI) supplemented with $2 \%$ bovine haemoglobin and $1 \%$ supplement B (BBL Microbiology Systems, Becton, Dickinson \& Co, Cockneysville, MD).$^{18}$ The isolates were grown overnight in chocolate agar and then suspended in tripticase soy broth. The reference strains of Neisseria gonorrhoeae included for daily quality control of the test were 76-061783, F-28, and F-29 from the Centers for Disease Control in Atlanta, GA. The cell suspension and inoculation of antibiotic containing plates were done as previously described in the literature. ${ }^{415} 18$ The MICs were determined as the lowest concentra- tion permitting the growth on no more than one colony.

Penicillin susceptible Neisseria gonorrhoeae isolates were defined as those having a MIC of $\leqslant 0.06 \mu \mathrm{g} / \mathrm{ml}$; intermediately penicillin resistant Neisseria gonorrhoeae had MICs in the range $0.06 \mu \mathrm{g} / \mathrm{ml}$ to $1.0 \mu \mathrm{g} / \mathrm{ml}$; and penicillin resistant Neisseria gonorrhoeae were those with MICs $\geqslant 1.0 \mu \mathrm{g} / \mathrm{ml}^{18}$ The PPNG and CMRNG isolates were included in the last group because the MICs of these strains were $\geqslant 1.0 \mu \mathrm{g} / \mathrm{ml}$. Spectinomycin susceptible isolates were those with MICs $<40 \mu \mathrm{g} / \mathrm{ml}$ and spectinomycin relatively resistant isolates were those with MICs $\geqslant 40 \mu \mathrm{g} / \mathrm{ml}^{18}$

\section{Results}

Investigators were unable to evaluate 133 patients either because they did not comply with the test of cure 3 to 10 days after treatment or did have a positive rectal or oral culture (69 were from the spectinomycin group). Thus, 400 of the 533 subjects who had had a positive genital culture for Neisseria gonorrhoeae were evaluated. Patients with post-gonococcal urethritis were all treated with oral tetracycline hydrochloride (500 mg 4 times per day for at least 7 days).

Of the subjects that were evaluated, the aqueous procaine penicillin G (APPG) plus probenecid was given to 190 patients ( 164 men and 26 women) while 210 patients (189 men and 21 women) received spectinomycin. The patients who received spectinomycin had a mean age of 26 years (range, 18-53 years); 134 were single and 72 were married; 186 were heterosexuals and 20 were male homosexuals. The patients in the APPG regimen had a mean age of 26

Table 2 MIC of penicillin and spectinomycin for isolates of Neisseria gonorrhoeae from patients with a given drug regimen

\begin{tabular}{|c|c|c|c|c|c|c|}
\hline \multirow[b]{3}{*}{ Drug regimen } & \multirow{3}{*}{$\begin{array}{l}\text { Number } \\
\text { tested }\end{array}$} & \multicolumn{5}{|c|}{ Number of isolates } \\
\hline & & \multicolumn{3}{|c|}{ MIC of penicillin $(\mu \mathrm{g} / \mathrm{ml})$} & \multicolumn{2}{|c|}{$\begin{array}{l}\text { MIC of spectinomycin } \\
(\mu \mathrm{g} / \mathrm{ml})\end{array}$} \\
\hline & & $(\leqslant 0.06)$ & $(0 \cdot 125-0.50)$ & $(\geqslant 1.0)$ & $<40$ & $\geqslant 40$ \\
\hline $\begin{array}{l}\text { Aqueous procaine penicillin G plus } \\
\text { probenecid } \\
\text { Spectinomycin } \\
\text { Total number of isolates (\%) }\end{array}$ & $\begin{array}{l}190 \\
210 \\
400\end{array}$ & $\begin{array}{rr}52 & \\
59 & \\
111 & (28)\end{array}$ & $\begin{aligned} 84 & \\
95 & \\
179 & (45)\end{aligned}$ & $\begin{array}{rr}54 & \\
56 & \\
110 & (27)\end{array}$ & $\begin{array}{ll}161 & \\
177 & \\
338 & (84)\end{array}$ & $\begin{array}{ll}29 & \\
33 & \\
62 & (16)\end{array}$ \\
\hline
\end{tabular}


Table 3 Results of treatment in each drug regimen according to MIC ranges and penicillin resistant isolates

\begin{tabular}{|c|c|c|c|c|}
\hline \multirow[b]{2}{*}{$\begin{array}{l}\text { Percentage of treatment failure in each drug regimen } \\
\text { Aqueous procaine penicillin } G \\
\text { plus probenecid }\end{array}$} & \multicolumn{2}{|c|}{ MIC range of penicillin $(\mu \mathrm{g} / \mathrm{ml})$} & \multicolumn{2}{|c|}{ Penicillin resistant isolates* } \\
\hline & $\begin{array}{l}<1.0 \\
2.9 \% \\
(4 / 136)\end{array}$ & $\begin{array}{ll}\geqslant & 1 \cdot 0 \\
& 24 \% \\
& (13 / 54)\end{array}$ & $\begin{array}{l}\text { PPNGs } \\
36 \% \\
(5 / 14)\end{array}$ & $\begin{array}{l}\text { CMRNGs } \\
20 \% \\
(8 / 40)\end{array}$ \\
\hline & \multicolumn{4}{|c|}{ MIC range of spectinomycin $(\mu \mathrm{g} / \mathrm{ml})$} \\
\hline \multirow[t]{2}{*}{ Spectinomycin } & $<40$ & $\geqslant 40$ & & \\
\hline & $\begin{array}{l}2.8 \% \\
(5 / 177)\end{array}$ & $\begin{array}{c}0 \% \\
(0 / 33)\end{array}$ & $\begin{array}{l}0 \% \\
(0 / 16)\end{array}$ & $\begin{array}{c}5 \% \\
(2 / 40)\end{array}$ \\
\hline
\end{tabular}

*There were 110 penicillin-resistant isolates (those with MICs $\geqslant 1.0 \mu \mathrm{g} / \mathrm{ml}$ ). PPNGs and CMRNGs stand for penicillin-producing Neisseria gonorrhoeae and chromosomally mediated-resistant Neisseria gonorrhoeae isolates, respectively.

years (range, 18-50 years); 129 were single and 58 were married; 165 were heterosexuals and 22 were male homosexuals. Information of social status and sexual preference was not recorded for seven males. Thus, both groups had similar characteristics. This was consistent with the randomised patient assignment used for this study.

There were no serious adverse reactions or side effects seen in either treatment group. However, postgonoccocal urethritis (defined as 4 or more pus cells per field in a gram-stained smear $\times 1000$ and a negative culture for Neisseria gonorrhoeae) was observed in 61 patients ( 27 spectinomycin; 34 APPG plus probenecid).

The follow-up results are shown in table 1 . None of the patients who failed to be cured using either penicillin or spectinomycin admitted re-exposure between visits. All treatment failures with either antibiotic regimen were cured after being retreated with spectinomycin. The penicillin regimen was effective in $91.1 \%$ of the patients while the spectinomycin regimen was effective in $97.6 \%$. A chi-square test of the frequencies of cure in each group confirmed that the observed difference was significant $(X(1)=8 \cdot 31$, $p$ $\leqslant 0.01)$. Although the sample size of women is small (47) for making conclusions, three of 26 patients treated with penicillin failed to cure and none of 21 treated with spectinomycin failed to cure. These observations among women followed the general trend of entire sample of 400 patients (see table 1 ).

The number of isolates and treatment failures in

Table 4 MIC50 and MIC90* of Neisseria gonorrhoeae isolatest to penicillin and spectinomycin

\begin{tabular}{llcc}
\hline $\begin{array}{l}\text { Antimicrobial } \\
\text { agent }\end{array}$ & $\begin{array}{l}\text { MIC range } \\
(\mu \mathrm{g} / \mathrm{ml})\end{array}$ & $\begin{array}{l}\text { MIC50 } \\
(\mu \mathrm{g} / \mathrm{ml})\end{array}$ & $\begin{array}{c}\text { MIC90 } \\
(\mu \mathrm{g} / \mathrm{ml})\end{array}$ \\
\hline Penicillin & $0.004-8.0$ & 0.25 & 2.0 \\
Spectinomycin & $2.5-80$ & 20.0 & 40.0 \\
\hline
\end{tabular}

*The MIC50 and the MIC90 are the concentrations required to inhibit $50 \%$ and $90 \%$ of the strains, respectively.

tThe MICs of penicillin and spectinomycin were determined for 533 isolates. each drug regimen are presented with their corresponding MICs to the study drugs in tables 2 and 3 . These data show the relationship of susceptibilities to efficacy. There was no significant relationship of elevated MICs to spectinomycin with failure to respond to therapy.

Among patients receiving the APPG regimen, there was a positive relationship between the number of patients not cured and the number of isolates with the higher MICs. The strains with MICs $\geqslant 1.0 \mu \mathrm{g} / \mathrm{ml}$ had failure rates of $2.9 \%$, while isolates with increased resistance to penicillin, MIC $\geqslant 1.0 \mu \mathrm{g} / \mathrm{ml}$, had failure rates of $24 \%$ (see table 3 ). The failure rates in the two groups were significantly different $(X(1)=16 \cdot 56, p \leqslant$ 0.01 ).

A total of 110 isolates of Neisseria gonorrhoeae had increased resistance for penicillin (MIC $\geqslant 1.0 \mu \mathrm{g} / \mathrm{ml}$ ). Eighty of these isolates were CMRNG and 30 were PPNG strains. The distribution of these strains by MICs and results of treatment for each antibiotic regimen are summarised in table 3 . In the PPNG strains, $36 \%$ of those treated with penicillin failed to respond, while no treatment failures were observed with spectinomycin. In the CMRNG strains, $20 \%$ of those treated with penicillin failed to respond, whereas $5 \%$ of those treated with spectinomycin failed to respond.

The MIC50 and MIC90 to penicillin and spectinomycin were determined for 533 isolates (table 4). The MIC range and the MIC50 and MIC90 of penicillin and spectinomycin for the 400 isolates from patients with cures are identical. This finding means that the susceptibility pattern of the $\mathbf{4 0 0}$ isolates was similar to the total pool of isolates and similar cure rates will be expected with the $25 \%$ dropout patients.

\section{Discussion}

A high prevalence (16\%) of CMRNG strains (MICs $\geqslant 1.0 \mu \mathrm{g} / \mathrm{ml}$ ) were reported in Puerto Rico in $1981 . .^{18}$ The number of CMRNG seen is high compared with that seen in the United States ${ }^{4910}$ and in South Africa ${ }^{19}$ but similar to other countries. ${ }^{16}$ Our results 
show a slight increase to $20.5 \%$. Of the 369 non-betalactamase producing strains, $72.3 \%$ were found to require penicillin MICs of $\leqslant 1.0 \mu \mathrm{g} / \mathrm{ml}$, and they were classified either as penicillin susceptible (MICs $\leqslant 0.06$ $\mu \mathrm{g} / \mathrm{ml}$ ) or intermediate resistant strains (MICs $>0.06$ $\mu \mathrm{g} / \mathrm{ml}$ and $<1.0 \mu \mathrm{g} / \mathrm{ml}$ ). This percentage is significantly higher than that reported for the United States $^{4620-23}$ but similar to other countries. ${ }^{11624}$

The incidence of PPNGs from 1981 to 1984 in Puerto Rico were $0.0 \%, 0.7 \%, 1.0 \%$, and $8.6 \%$, respectively. The presence of a fair number of PPNG isolates during the study was due to a large outbreak during 1984. Since control efforts are lacking for CMRNG and travel from areas of high prevalence caused periodic outbreaks of PPNG in Puerto Rico, a rapid increase in penicillin-resistant strains can be expected to occur at any time.

The treatment failures observed while using penicillin against strains with MICs $<1.0 \mu \mathrm{g} / \mathrm{ml}$ is very low and comparable to other reports. ${ }^{1-4}$ The positive relationship of penicillin failures with CMRNG strains (MICs $\geqslant 1.0 \mu \mathrm{g} / \mathrm{ml}$ ) has been previously observed. ${ }^{4}$ The presence of CMRNG strains should be of great concern for countries in the Carribean and Latin America that still used APPG regimen for gonorrhoea. Therefore, surveillance of these strains should be highly encouraged. ${ }^{10}$ In our opinion, a failure rate of greater than $5 \%$, as seen with the APPG plus probenecid regimen in Puerto Rico, does not guarantee effective control of gonorrhoea.

The MIC50 and MIC90 to spectinomycin were higher than in other countries. ${ }^{46131920}$ Perhaps this is due to the frequency of spectinomycin use in Puerto Rico for gonococcal infection. Like others whose work precedes ours, we were unable to relate spectinomycin treatment failures with in vitro spectinomycin susceptibility. ${ }^{1-5}$ The spectinomycin regimen was also effective for PPNG, CMRNG (5\% failure rate), and beta-lactamase negative strains, also reported by others. ${ }^{4581125}$

Factors contributing to treatment failure seen with spectinomycin in this study are still undefined since all isolates with MICs of $40-80 \mu \mathrm{g} / \mathrm{ml}$ responded to therapy. Our results showed that the in vitro break point for clinical resistance is probably higher than presently recommended. The few clinical failures with spectinomycin were probably due to reinfections or patients' immunological differences.

Recently, Boslego and coworkers ${ }^{26}$ reported the emergence of a substantial prevalence of clinical treatment failures caused by spectinomycin-resistant strains (MIC $\geqslant 100 \mu \mathrm{g} / \mathrm{ml}$ ) in a geographic region where spectinomycin had been used in the primary treatment of gonococcal infection for only three years. Since the completion of the clinical study, we initiated a surveillance program to monitor the emergence of resistant strains to spectinomycin using sensitivity testing with $100 \mu \mathrm{g}$-spectinomycin disk and agar dilution. We have documented only a few sporadic (2) cases in a four year period, but a cautious approach to the widespread use of spectinomycin is recommended. Public health officials in the area must remain vigilant in their surveillance effort and be alert to the introduction or emergence of spectinomycin-resistant strain.

There were no serious adverse reactions found with either the APPG plus probenecid or spectinomycin regimens. APPG plus probenecid could be used in Puerto Rico only in clinics that have surveillance for PPNG and CMRNG strains. However, spectinomycin could be given as an alternative for the treatment of genital gonorrhoea because of the high prevalence of CMRNG and PPNG strains and the high rate of failure seen with the use of penicillin. Current recommendations include a course of tetracycline or erythromycin for non-gonococcal urethritis (dual therapy) added to spectinomycin (or ceftriaxone) for genital gonorrhoea. ${ }^{27}$

The authors thank The Upjohn Company of Kalamazoo, Michigan, USA for its support of the research presented here. We thank Dr Ronald K St John and Dr Fernando Zacarias of the Pan American Health Organization (PAHO) for their guidance, support, and cooperation in this study. Without the assistance of Mr E Rivera, Ms L Santos, Mr J Méndez, and the staff of the Latin American Center for STD this research could not have been completed. The authors also appreciate the assistance offered by $\mathrm{Dr}$ John D Balling of the Harvard Institute for International Development.

\section{References}

1 Ratnam AV, Patel MI, Hira SK, et al. Penicillin and spectinomycin in the treatment of gonococcal urethritis. Sex Transm Dis 1982;9:135-7.

2 Kaufman RE, Johnson RE, Jaffe HW, et al. National gonorrhoea therapy monitoring study: treatment results. $N$ Engl $J$ Med 1976;294:1-4.

3 Finger AH. Spectinomycin in the treatment of gonorrhoea therapy males. Br J Venereal Dis 1975;51:38-40.

4 Jaffe HW, Biddle JW, Thornsberry C, Johnson RE, Reynolds GH, Wiesner PJ, and the Cooperative Study Group. National gonorrhoea therapy monitoring study: in vitro antibiotic susceptibility and its correlation with treatment results. $N$ Engl J Med 1976;294:5-9.

5 Jaffe HW, Biddle JW, Johnson SR, Wiesner P. Infection due to penicillinase-producing Neisseria gonorrhoea in the United States from 1976 to 1980. J Infect Dis 1981;144:191-7.

6 Thornsberry C, Biddle JW, Perine PL, Siegel MS. Susceptibility of Neisseria gonorrhoea from the United States and the Far East (beta-lactamase negative and positive). In: Brooks GF, Gotschlinch FC, Holmes KK, Sawyer WD, Young FE, eds. Immunology of Neisseria gonorrhoea. Washington, DC. Am Soc Microb, 1978. 
7 World Health Organization. Neisseria gonorrhoea producing betalactamase (penicillinase). Weekly Epidemiol Record 1977; 52:357-8.

8 Centers for Disease Control. Follow-up on penicillinaseproducing Neisseria gonorrhoea worldwide. MMWR 1977; 26(1):153-4.

9 Centers for Disease Control. Penicillin-resistant gonorrhoeaNorth Carolina. MMWR 1983;32:273-5.

10 Centers for Disease Control. Chromosomally mediated Neisseria gonorrhoea-United States. MMWR 1984;32(28):408-10.

11 Crider SR, Colby SD, Miller LK, et al. Treatment of penicillinresistant Neisseria gonorrhoea with oral Norfloxacin. $N$ Engl J Med 1984;311:137-40.

12 Reyn A, Schmidt H, Trier M, Bentzon M. Spectinomycin hydrochloride (trobicin) in the treatment of gonorrhoea: observation of resistant strains of Neisseria gonorrhoea. $\mathrm{Br} J$ Venereal Dis 1973;49:54-9.

13 Meheus A, Piot P, Pattyn S, Vandyck E, Vanden-Berghe D. Activity in vitro of ten antimicrobial agents against Neisseria gonorrhoea: a study of the correlation between the sensitivities. Br J Venereal Dis 1976;52:329-32.

14 Thornsberry C, Jaffe HW, Brown ST, Edwards T, Biddle JW, Thompson III SE. Spectinomycin resistant Neisseria gonorrhoeae. JAMA 1977;237:2405-6.

15 Morello JA, Bonhoff M. Neisseria and Brahamella. In: Lenette EH, Balows A, Hunsler W, Truant JP, eds. Manual of clinical microbiology. Washington, DC. Am Soc Microb 1980:11-30.

$16 \mathrm{Ng}$ WS, Anton P, Arnold K. Neisseria gonorrhoea strain isolates in Hong Kong: in vitro susceptibility to 13 antibiotics. Antimicrob Agents Chemother 1981;19:12-7.

17 Thornsberry C. United States Department of Health Education and Welfare, Center for Disease Control (DHEW Publication No. CDC-80-42) Atlanta, GA, 1979.

18 Rodriguez J, Fuxench-Chiesa $\mathrm{Z}$, Ramirez-Ronda $\mathrm{CH}$, et al. In vitro susceptibility of 50-non-beta-lactamase producing Neisseria gonorrhoea strains to 12 antimicrobial agents. Antimicrob
Agents Chemother 1983;23:242-4.

19 Leibowitz LD, Ballard RC, Koorhof HJ. In vitro susceptibility and cross resistance of South African isolates of Neisseria gonorrhoea to 14 antimicrobial agents. Antimicrob Agents Chemother 1982;22:598-603.

20 Hall WH, Schierl EA, Maccani JE. Comparative susceptibility of penicillinase-positive and negative Neisseria gonorrhoea to 30 antibodies. Antimicrob Agents Chemother 1979;15:562-7.

21 Baker CN, Thornsberry C, Jones RN. In vitro antimicrobial activity of cefoperazone, defotaxime, moxalactam (LY127935), azlocillin, mezlocillin, and other beta-lactam antibiotics against Neisseria gonorrhoea and Haemophilus influenzae, including beta-lactamase-producing strains. Antimicrob Agents Chemother 1980;17:757-61.

22 Khan MY, Siddiqui Y, Simpson ML, Gruninger RP. Comparative in vitro activity of cefmenoxime, cefotaxime, cefuroxime, cefoxitin, and penicillin against Neisseria gonorrhoea. Antimicrob Agents Chemother 1981;20:681-2.

23 Cohen MS, Huck-Cooney M, Blackman E, Sparking F. In vitro antimicrobial susceptibility of penicillinase-producing and intrinsically resistant Neisseria gonorrhoea strains. Antimicrob Agents Chemother 1983;24:597-9.

24 Piziak MV, Woodbury C, Berliner D, et al. Resistance trends of Neisseria gonorrhoea in the Republic of Korea. Antimicrob Agents Chemother 1984;25:7-9.

25 Kousa M, Lassus A, Jarvelainen R, Renkonen O-V. Spectinomycin hydrochloride in the treatment of uncomplicated gonorrhoeae in males and females. Br J Venereal Dis 1974;50:291-3.

26 Boslego JW, Tramont EC, Takafuji ET, et al. Effect of spectinomycin use on the prevalence of spectinomycin-resistant and penicillinase-producing Neisseria gonorrhoea. $N$ Engl J Med 1987;317:272-8.

27 Gadea C, Gonzalez LI, Menar R, et al. Nueva recomendación en el tratamiento de infecciones genitales causadas por Neisseria gonorrhoea en Puerto Rico. Bol Assoc Med P Rico 1985;77: $343-4$. 